OPEN ACCESS

Edited by:

Yun-Cai Liu,

Tsinghua University, China

Reviewed by:

Jinfang Zhu,

National Institute of Allergy and Infectious Diseases (NIAID),

United States

Koji Yasutomo,

Tokushima University, Japan

${ }^{*}$ Correspondence:

Xiao-Ping Zhong

xiaoping.zhong@duke.edu

Specialty section

This article was submitted to

T Cell Biology,

a section of the journal

Frontiers in Immunology

Received: 23 April 2019 Accepted: 04 November 2019 Published: 21 November 2019

Citation:

Tao H, Li L, Gao Y, Wang Z and Zhong X-P (2019) Differential Control of iNKT Cell Effector Lineage Differentiation by the Forkhead Box Protein 01 (Foxo1) Transcription Factor. Front. Immunol. 10:2710. doi: 10.3389/fimmu.2019.02710

\section{Differential Control of iNKT Cell Effector Lineage Differentiation by the Forkhead Box Protein 01 (Foxo1) Transcription Factor}

\author{
Huishan Tao ${ }^{1,2}$, Lei Li ${ }^{1,3}$, Ying Gao ${ }^{2}$, Zehua Wang ${ }^{2}$ and Xiao-Ping Zhong ${ }^{1,4,5 *}$ \\ ${ }^{1}$ Department of Pediatrics-Allergy and Immunology, Duke University Medical Center, Durham, NC, United States, \\ ${ }^{2}$ Department of Gynecology and Obstetrics, Union Hospital, Tongji Medical College, Huazhong University of Science and \\ Technology, Wuhan, China, ${ }^{3}$ Department of Breast and Thyroid Surgery, Union Hospital, Tongji Medical College, Huazhong \\ University of Science and Technology, Wuhan, China, ${ }^{4}$ Department of Immunology, Duke University Medical Center, Durham, \\ NC, United States, ${ }^{5}$ The Hematologic Malignancies and Cellular Therapy Research Program, Duke Cancer Institute, \\ Duke University Medical Center, Durham, NC, United States
}

The invariant NKT (iNKT) cells recognize glycolipid antigens presented by the non-classical MHC like molecule CD1d. They represent an innate T-cell lineage with the ability to rapidly produce a variety of cytokines in response to agonist stimulation to bridge innate and adaptive immunity. In thymus, most iNKT cells complete their maturation and differentiate to multiple effector lineages such as iNKT-1, iNKT-2, and iNKT-17 cells that possess the capability to produce IFN $\gamma, \mathrm{IL}-4$, and IL-17A, respectively, and play distinct roles in immune responses and diseases. Mechanisms that control iNKT lineage fate decisions are still not well understood. Evidence has revealed critical roles of Foxo1 of the forkhead box $\mathrm{O} 1$ subfamily of transcription factors in the immune system. However, its role in iNKT cells has been unknown. In this report, we demonstrate that deletion of Foxo1 causes severe decreases of $i N K T$ cell total numbers due to impairment of late but not early iNKT cell development. Deficiency of Foxo1 results in decreases of $i N K T-1$ but increases of $i \mathrm{NKT}-17$ cells. Our data reveal that Foxo1 controls $i$ NKT effector lineage fate decision by promoting iNKT-1 but suppressing iNKT-17 lineages.

Keywords: invariant NK T cells, iNKT cells, Foxo1, T-bet, ROR $\gamma$ t, T cell development, IFN $\gamma$, IL-17A

\section{INTRODUCTION}

$i$ NKT cells express TCRs that contain an invariant TCRV $\alpha 14-\mathrm{J} \alpha 13$ (iV $\alpha 14$ ) chain paired with limited numbers of TCR $\beta$ chain that recognize glycolipid antigens presented by the non-classic MHC-I like molecule CD1d. They play important roles in immune responses and tissue repair but also contribute to the pathogenesis of diseases (1-4). The iV $\alpha 14$ TCR signaling via multiple pathways such as RasGRP1-Ras-Erk1/2 pathway, the PKC $\theta-\mathrm{NF} \kappa \mathrm{B}$ pathway, and mTOR is crucial for $i \mathrm{NKT}$ cell development in the thymus $(2,5-12)$. iNKT cells are traditionally defined into four developmental stages in the thymus: stage $0\left(\mathrm{CD} 24^{+} \mathrm{CD} 44^{-} \mathrm{NK} 1.1^{-}\right)$, stage 1 $\left(\mathrm{CD} 24^{-} \mathrm{CD} 44^{-} \mathrm{NK} 1.1^{-}\right)$, stage $2\left(\mathrm{CD} 24^{-} \mathrm{CD} 44^{+} \mathrm{NK} 1.1^{-}\right)$, and stage $3\left(\mathrm{CD} 24^{-} \mathrm{CD} 44^{+} \mathrm{NK} 1.1^{+}\right)$ $(13,14)$. Recently, $i \mathrm{NKT}$ cells have also been defined into multiple effector lineages based on expression of specific transcription factors and cytokines. These effector lineages identified thus far include IFN- $\gamma$-producing $i$ NKT1, IL-4-producing $i$ NKT2, IL-17A-producing $i$ NKT17, 
$i$ NKT10, Tfh-like $i$ NKTfh, and Treg-like $i$ NKT cells. $i$ NKT1, $i \mathrm{NKT} 2, i \mathrm{NKT} 17$, and $i \mathrm{NKTfh}$ cells express T-bet, Gata3, ROR $\gamma \mathrm{t}$, and $\mathrm{Bcl} 6$ that correspond to master transcription factors in individual $\mathrm{T}$ helper lineages, respectively (15-23). Stage $3 i \mathrm{NKT}$ cells are virtually all $i$ NKT1 cells $(15,24,25)$, while $i$ NKT17 cells reside in stage $2 \mathrm{CD}_{4} 4^{+} \mathrm{NK} 1.1^{-}$neuropilin $-1^{+} \mathrm{ICOS}^{+}$cells $(8,18,26-28)$. $i$ NKT2 cells can be found in both stage 1 and stage $2 i$ NKT cells (28). Individual $i$ NKT cell lineages exert distinct functions in immune responses and diseases. $i$ NKT cell derived IL-4 participates in regulation of early germinal center B cell responses (29), liver regeneration and repair after injury (30), and adipocyte homeostasis (31). iNKT cell derived IL17 exacerbates airway hypersensitivity by recruiting neutrophils and inducing smooth muscle contraction $(8,20)$. iNKTfh cells secrets IL-21 and provides direct cognate help to antigenspecific B cells (16). Different from conventional $\alpha \beta T$ cells, most $i$ NKT cells complete their effector lineage differentiation in the thymus and their relative abundance is influenced by genetic backgrounds, environmental factors, and intrinsic signal, metabolic, and transcriptional pathways. The mechanisms that control $i$ NKT cell effector lineage fate decision are still not fully understood.

Foxo1 belongs to the Forkhead box "O" subfamily of transcription factors binding to a consensus DNA sequence $5^{\prime}-(\mathrm{A} / \mathrm{C}) \mathrm{AA}(\mathrm{C} / \mathrm{T}) \mathrm{A}$ to regulate transcription of many genes involved in cell survival, cell cycle, differentiation, and cancer (32). Many mechanisms have evolved to regulate Foxol at both transcriptional and post transcriptional levels. A key mechanism is its phosphorylation by Akt and serum/glucocorticoid regulated kinase 1 (SGK1) on different sites that leads to its export from the nucleus and sequestration in the cytosol due to increased association to 14-3-3 proteins (33). Many studies have revealed important roles of the Foxo subfamily in the immune system $(32,34)$. Foxol promotes production of inflammatory cytokines in and regulates migration of dendritic cells $(35,36)$, is essential for B cell development and Ig class-switch (37-39), and regulates $\mathrm{T}$ cell differentiation and function (34). It controls $\mathrm{T}$ cell survival and homing via increasing IL7 receptor expression, CCR7, and L-selectin expression (40), plays important roles for regulatory $\mathrm{T}$ cell development and function (41-43), negatively controls Th17 cell differentiation (44-47) and Tfh differentiation (4850), promotes Th9 responses (51-53), and regulates CD8 $\mathrm{T}$ cell effetor/memory differentiation (54-56). We report here that deficiency of Foxol does not grossly affect early $i$ NKT cell development but severely impacts late $i \mathrm{NKT}$ cell development, manifested by severe reduction of $i$ NKT1 cells but increases of $i$ NKT17 cells. Our data suggest that Foxo1 is a critical regulator that controls $i \mathrm{NKT} 1$ and $i \mathrm{NKT} 17$ effector fate decision.

\section{MATERIALS AND METHODS}

\section{Mice}

Foxo $1^{f / f}$ and Cd2iCre mice were purchased from the Jackson Laboratory $(57,58)$. Foxo $1^{f / f}$ had further backcrossed to C57BL6/J background. Two to ten-week-old Foxo $1^{f / f}$-Cd2iCre and Foxol $1^{f / f}$ or Cd2iCre littermate control mice were used for the experiments. For each experiment, one pair of test and control mice of the same sex littermates examined. All mouse experiments were performed according to protocols approved by the Duke University Institute Animal Care and Use Committee.

\section{Assessment of Foxo1 Recombination}

Ten millions of viable $\mathrm{CD} 4^{+} \mathrm{CD}^{+}$thymocytes from ageand sex-matched Foxo $1^{f / f}$ and Foxo $1^{f / f}$-Cd2iCre mice were sorted on MoFlo Cell Sorter (Beckman Coulter) with postsort purity of $98 \%$. Genomic DNAs were extracted with phenol/chloroform, precipitated with $70 \%$ ethanol, dissolved in TE buffer ( $10 \mathrm{mM}$ Tris- $0.5 \mathrm{mM}$ EDTA $[\mathrm{pH} 8])$, and utilized as templates for PCR reaction. The forward and reverse primers for Foxo1 were 5'-ACCACTCTGGACGGCATACT$3^{\prime}$ and $5^{\prime}$-TAACATAAAGGGAGATGAAGCA-3', respectively. These two primers flank one of the two Loxp sites in the Foxo1 locus so that they did not amply a PCR product after Cre mediated recombination. Primers for Dgkz as control were $5^{\prime}$-AGAAAGCTGATCCCCCACAT- $3^{\prime}$ (forward) and $5^{\prime}$ AGAGAGCGTCCTTCAAGAGG-3' (reverse). PCR products were visualized after electrophoresis in $1 \%$ agarose gel.

\section{Flow Cytometry and Antibodies}

Thymocytes, splenocytes, and liver mononuclear cells were prepared according to published protocols $(9,10)$. Cells were stained for surface markers with appropriate fluorochromeconjugated antibodies in PBS containing 2\% FBS on ice for $30 \mathrm{~min}$ followed by intracellular staining of transcription factors using the BD Bioscience Transcription Factor Buffer Set or Ki67 using the BD Bioscience Cytofix/Cytoperm ${ }^{\mathrm{TM}}$ solution according to the manufacturer's protocols. Data were collected using a BD LSRFortessa ${ }^{\mathrm{TM}}$ cytometer (BD Biosciences). PE- or allophycocyanin-labeled PBS57-loaded CD1d tetramers (CD1dTet) were provided by the NIH Tetramer Core Facility. Fluorochrome-conjugated anti-CD45.2 (clone 104), CD45.1 (A20), TCR- $\beta$ (clone H57-597), NK1.1 (clone PK136), CD44 (clone IM7), CD24 (clone M1/69), CD11b (clone M170), CD11c (clone N418), F4/80 (clone BM8), B220 (clone RA3-6B2), TER119/Erythroid Cells (clone TER-119), CD4 (clone GK1.5), CD8a (clone 53-6.7), ICOS (clone C398.4A), T-bet (clone 4B10), IL7R $\alpha$ (clone SB/199) were purchased from Biolegend; anti-GATA3 (clone L50-823), CD122 (clone TM-b1), ROR $\gamma$ t (clone Q31-378), Streptavidin (BV711), and Ki67 were purchased from BD Biosciences; anti-PLZF (clone Mags.21F7) was purchased from eBioscience. Cell death was identified using the Live/Dead ${ }^{\mathrm{TM}}$ Fixable Violet Dead Cell Stain (Thermo Fisher Scientific). Reactive oxygen species (ROS) were detected with $2^{\prime}, 7^{\prime}$-dichlorodihydrofluorescein diacetate (H2DCFDA) (ThermoFisher). Goat anti-mouse IgG $(\mathrm{H}+\mathrm{L})$ antibody (Alexa Fluor 568) for detection of the anti-Ki67 antibody was purchased from Thermo Fisher Scientific. Data were analyzed using the FlowJo Version 9.2 software (Tree Star).

\section{Generation of Chimeric Mice}

$\mathrm{CD} 45.1^{+} \mathrm{CD} 45.2^{+} \mathrm{WT}$ mice in $\mathrm{C} 57 \mathrm{BL} / 6$ background were irradiated with a single dose of $800 \mathrm{rad}$ X-Ray and intravenously injected with 10-15 million of a mixture of BM cells from 
CD 45.1 ${ }^{+}$WT mice and CD 45.2 ${ }^{+}$Foxol $^{f / f}-C d 2 i C r e$ mice at $1: 1$ ratio. Recipient mice were euthanized and analyzed 8 weeks later.

\section{Statistical Analysis}

Data were presented as mean \pm SEM and analyzed for statistical differences using the Prism 5/GraphPad software. Comparisons were made using the two-tailed paired or unpaired Student $t$-test. Each pair represents age- and sex-matched littermates that were examined in a single experiment and is indicated by a connecting line between test and control mice. $P$-values less than 0.05 were considered significant $\left({ }^{*} p<0.05,{ }^{* *} p<0.01,{ }^{* * *} p<0.001\right)$.

\section{RESULTS}

\section{Impairment of iNKT Cell Development in Foxo1 ${ }^{f / f}-$ Cd2iCre Mice}

To investigate the role of Foxol in $i$ NKT cell development, we bred Foxol $f / f$ mice (57) with hCD2-iCre (Cd2iCre) mice (58) to
A

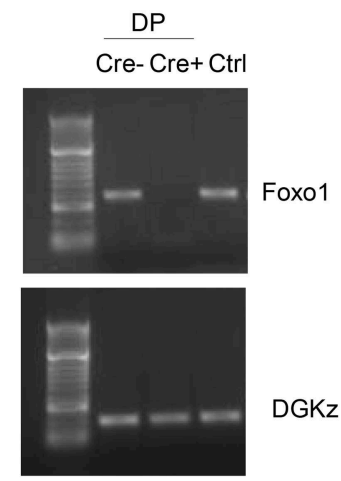

B

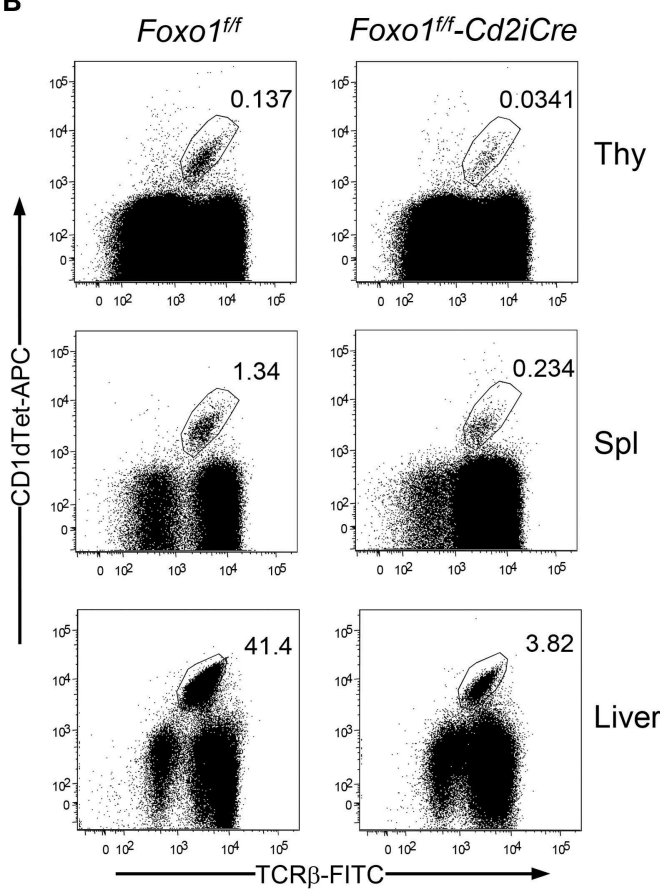

C

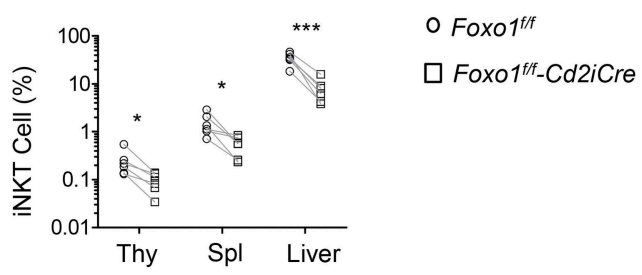

D

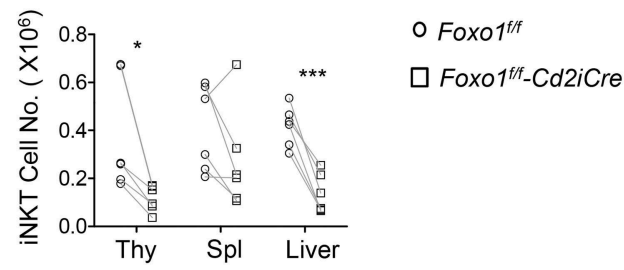

E

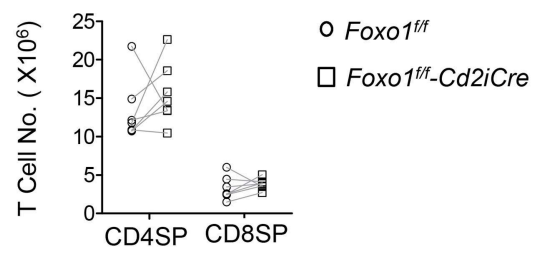

FIGURE 1 | Severe decreases of $i$ NKT cells in Foxo $1^{f / f}$-Cd2iCre mice. Six to ten weeks old Foxo $1^{t / f}$-Cd2iCre (Foxo1KO) and Foxo $1^{t / f}$ or Cd2iCre controls (Ctrl) mice were analyzed for iNKT cells by flow cytometry. (A) Assessment of Cre mediated deletion in Foxo1 gene in DP thymocytes. Cre mediated recombination causes deletion of the PCR template. Cre-: Foxo $1^{f / f}$; Cre+: Foxo $1^{f / f}$-Cd2iCre; Ctrl: tail DNA from Foxo ${ }^{f / f}$-Cd2iCre mice. (B) TCR $\beta$ and CD1dTet staining of thymocytes, splenocytes, and liver mononuclear cells (MNCs). Live gated Lin-singlets are shown. (C) Percentages of iNKT cells in the indicated organ. (D) Numbers of iNKT cells in the indicated organs. (E) TCR $\beta^{+}$SP thymocyte numbers. FACS plots are representative of five experiments. Scatter plots are pooled from five experiments (C,D) or seven experiments (E). Each circle and square represents one WT and one Foxo1KO mice, respectively. Connecting lines indicate individual pairs of sex-and age-matched test and control mice in each experiment. One pair of mice was examined in each experiment. ${ }^{*} p<0.05 ;{ }^{* \star *} p<0.001$ determined by two-tail pair-wised Student $t$-test. 
generate Foxo1 $1^{f / f}$-Cd2iCre (Foxo1KO) mice. CD2iCre induces gene ablation of floxed genes in both T cells and $\mathrm{B}$ cells (58) and in $\mathrm{CD}^{+}{ }^{+} \mathrm{CD} 8^{+}$double positive (DP) thymocytes (Figure 1A). We used TCR $\beta$ and PBS-57 loaded CD1d tetramer (CD1dTet) to detect $i$ NKT cells. In Foxo $1^{f / f}-C d 2 i C r e$ mice, TCR $\beta^{+}$CD1dTet ${ }^{+}$ $i$ NKT cell percentages and numbers were decreased $64.41 \%$ and $68.56 \%$, respectively in the thymus compared with Foxol ${ }^{f / f}$ controls (Figures 1B-D). Moreover, $i$ NKT cell percentages and numbers were also reduced in the spleen and liver in Foxo ${ }^{f / f}$. Cd2iCre mice with the exception of splenic $i$ NKT cells in one Foxol $1^{f / f}$-Cd2iCre mice due severe splenomegaly likely caused by defective function of regulatory $\mathrm{T}$ cells. In contrast, $\mathrm{CD}^{+}{ }^{+} \mathrm{CD} 8^{-}$single positive (SP) $\mathrm{TCR}^{+}$and $\mathrm{CD} 4^{-} \mathrm{CD} 8^{+} \mathrm{SP}$ TCR $\beta^{+}$thymocyte numbers were similar between control and Foxo1KO mice (Figure 1E). Thus, Foxo1 deficiency resulted in severe impairment of $i$ NKT cell but not conventional $\alpha \beta T$ cell development.

\section{Intrinsic Control of iNKT Development by Foxo1}

Because Foxol was ablated in both $\mathrm{T}$ and $\mathrm{B}$ cell lineages and Foxo1 deficiency causes severe $\mathrm{B}$ cell developmental defects, impairment of regulatory $\mathrm{T}$ cell function, and $\mathrm{Th}$ lineage and CD8 effector/memory differentiation $(32,59)$, the severe decreases of $i \mathrm{NKT}$ cells could result from change of environment in these mice. To determine if abnormal $i \mathrm{NKT}$ cell development in Foxolf/f-Cd2iCre mice was autonomous, we generated mixed bone marrow (BM) irradiation chimeric mice by injecting a mixture of CD45.1 ${ }^{+} \mathrm{WT}$ and CD45.2 $2^{+}$ Foxo $1^{f / f}$-Cd2iCre BM cells at a $1: 1$ ratio into sublethally irradiated CD $45.1^{+} \mathrm{CD} 45.2^{+}$recipient mice. Two months after reconstitution, recipient mice contained about $1: 1$ ratio of CD $45.2^{+}$and CD 45. $1^{+}$CD $11 b^{+}$Ly6G $^{+}$Ly6C $^{-}$neutrophils in the spleen (Figures 2A,B) suggesting equal reconstitution of these two types of hematopoietic stem cells (HSCs). Additionally, the ratios of $\mathrm{CD} 45.2^{+}$to $\mathrm{CD} 45.1^{+} \mathrm{CD} 4^{+} \mathrm{CD} 8^{+}$double positive (DP) thymocytes, the immediate precursors of $i \mathrm{NKT}$ cells, and non- $i \mathrm{NKT}$ TCR $\beta^{+}$conventional $\mathrm{T}$ cells were also 1:1 (Figures 2C,D,F). However, the CD45.2 ${ }^{+}$Foxo1KO to CD45.1 WT ratios for $i$ NKT cells were drastically decreased to $0.2: 1$ (Figures 2D,F). In contrast, the ratio for CD1dTet ${ }^{-} \mathrm{TCR} \beta^{+}$ conventional $\alpha \beta \mathrm{T}$ cells in the thymus were not decreased (Figures 2D,F). Consistent with severe defects in $i$ NKT cell generation, very few $i \mathrm{NKT}$ cells in the spleen and liver in the recipients were derived from Foxo1KO HSCs (Figures 2E,F). Thus, Foxol deficiency intrinsically inhibited $i$ NKT but not conventional $\alpha \beta$ T cell development.

\section{Foxo1 Deficiency Caused Impairment of Late Stage iNKT Cell Development}

$i \mathrm{NKT}$ cell development in the thymus is traditionally defined sequentially into $\mathrm{CD} 24^{+} \mathrm{CD} 44^{-} \mathrm{NK} 1.1^{-}$stage 0 , $\mathrm{CD} 24^{-} \mathrm{CD} 44^{-} \mathrm{NK} 1.1^{-}$stage $1, \mathrm{CD} 24^{-} \mathrm{CD} 44^{+} \mathrm{NK} 1.1^{-}$stage 2 , and $\mathrm{CD} 24^{-} \mathrm{CD} 44^{+} \mathrm{NK} 1.1^{+}$stage $3(13,14)$. In Foxolf/f Cd2iCre mice, stage 0 iNKT cell percentages were increased but numbers were not altered compared with control mice
(Figures 3A,B). Stages 1 and $2 i \mathrm{NKT}$ cell percentages displayed increased trend, although not statistically significant. However, their numbers were not obviously altered (Figures 3A,C). Importantly, stage $3 i \mathrm{NKT}$ cell percentages and numbers were both decreased in Foxol $f / f-C d 2 i C r e$ thymus (Figures 3A,C). In Foxo1KO spleen, stage $2 i \mathrm{NKT}$ cell numbers were similar to WT control but stage 3 showed decreased except one mouse (Figure 3D), which contained increased stage $3 i \mathrm{NKT}$ cells due to considerable enlargement of the spleen that was likely caused defects in regulatory $\mathrm{T}$ cells and lymphoproliferative disorders. In Foxo1KO liver, stage $2 i \mathrm{NKT}$ cell numbers were also similar to WT control but stage $3 i \mathrm{NKT}$ cells were obviously decreased (Figure 3E). Thus, Foxol deficiency appears to selectively affect late stage $i \mathrm{NKT}$ cell development.

\section{Intrinsic Promotion of Late Stage iNKT Maturation by Foxo1}

We further examined whether Foxol intrinsically promotes late stage $i \mathrm{NKT}$ cell maturation using the mixed BM chimeric mice described in Figure 2. Within CD $45.2^{+}$Foxo1KO $i$ NKT cells, the percentages of stages 0,1 , and 2 were increased $11.08,2.54$, and 1.87 folds compared with CD45.1 ${ }^{+}$WT $i$ NKT cells, respectively; but stage 3 were drastically decreased (Figures 4A,B), indicating an intrinsic role of Foxol for $i \mathrm{NKT}$ cell terminal maturation to stage 3 . Because $i$ NKT cells were predominantly stage 3 and its dramatic decreases could affect the percentages of stage $0-2$ $i$ NKT cells, we further calculated CD45.2 Foxo1KO/CD45.1 WT ratios of each stage of $i \mathrm{NKT}$ cells in individual recipient mice. As shown in Figures 4C,D, the ratios of CD45.2/CD45.1 of stage 0 $i$ NKT cell were increased to 3.4:1 compared with the ratios of DP thymocytes. But the ratios of stages 1, 2, and 3 were progressively decreased from $0.60: 1$, to $0.35: 1$, and finally to $0.073: 1$. These results suggested that Foxo1 deficiency exerted weak inhibition on stage 1 and stage $2 i$ NKT cell maturation but much strong impact on stage $3 i \mathrm{NKT}$ cell maturation. The increases of stage 0 ratios could be caused by enhanced early $i$ NKT cell generation and/or blockade of stage 0 to stage $1 \mathrm{iNKT}$ cell transition in the absence of Foxo1. Thus, Foxol intrinsically promoted $i$ NKT cell maturation, particularly late stage maturation.

\section{Differential Effects of Foxo1 Deficiency on iNKT Effector Lineage Differentiation}

$i \mathrm{NKT}$ cells differentiate to multiple effector lineages in the thymus that can be defined based expression transcriptional factors/repressors PLZF, GATA3, T-bet, and ROR $\gamma \mathrm{t}$ (15). Within $i$ NKT cells from Foxo1 $f / f-C d 2 i C r e$ thymus, the percentages of $\mathrm{PLZF}^{+} \mathrm{GATA}^{+} i \mathrm{NKT} 2$ and $\mathrm{ROR}^{+} \mathrm{t}^{+} \mathrm{T}^{-}$bet $^{-} i \mathrm{NKT} 17$ cells were increased but ROR $\gamma \mathrm{t}^{-} \mathrm{T}^{-\mathrm{bet}^{+}}{ }^{+} \mathrm{NKT} 1$ cells were decreased (Figures 5A,B). Thus, Foxol deficiency greatly inhibited $i$ NKT1 development, which was consistent with severe decreases of stage $3 i$ NKT cells that are mostly $i$ NKT1 cells.

\section{Intrinsic Control of iNKT Effector Lineage Differentiation by Foxo1}

Because $i$ NKT effector lineages may compete with each other during development and are influenced by thymic environment, 
A

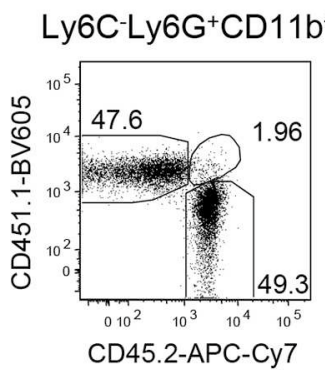

B

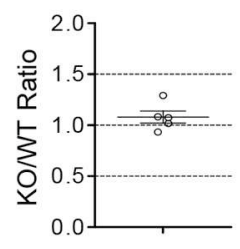

C

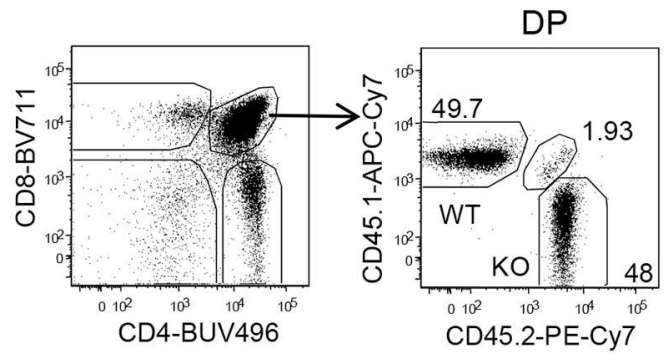

D

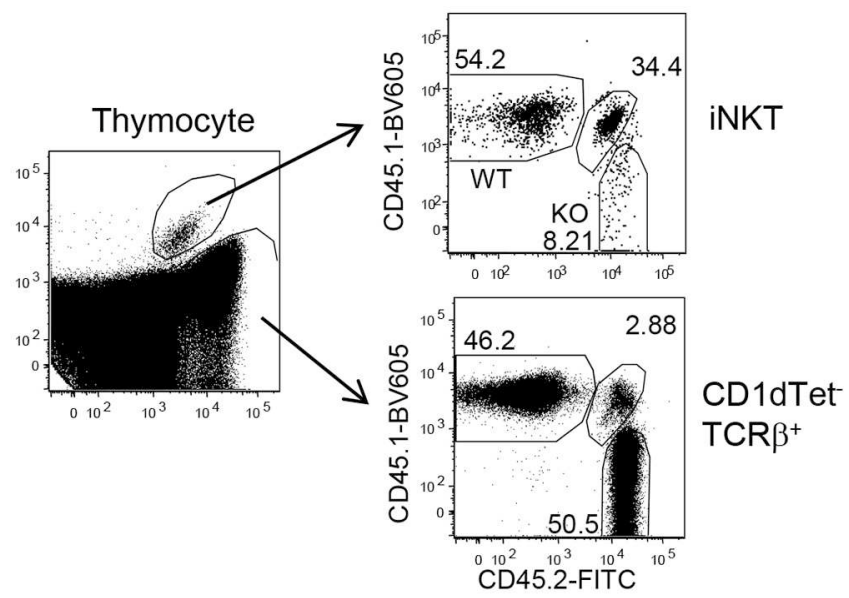

E

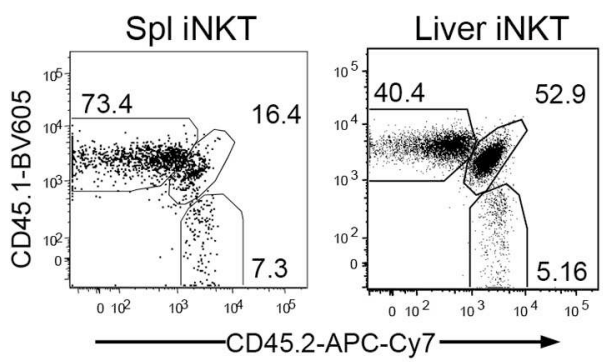

F

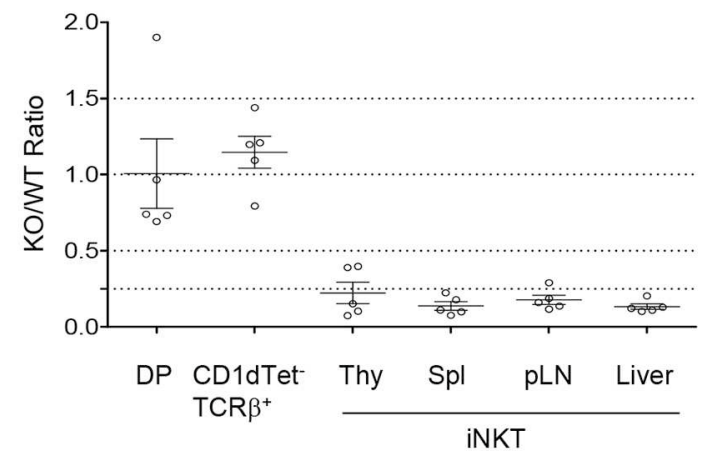

FIGURE 2 | Intrinsic control of $i$ NKT cell development by Foxo1. CD45.1+CD45.2+ WT mice were irradiated with 800 rad X-ray and intravenously injected with a mixture of CD45.1 $1^{+}$WT and CD45.2 $2^{+}$Foxo $1^{f / f}$-Cd2iCre BM cells at a 1:1 ratio. Recipient mice were euthanized and analyzed 2 months after reconstitution. 
FIGURE 2 | (A) Representative FACS plots showing CD45.1 and CD45.2 staining in splenic Ly6C ${ }^{-}$Ly6G ${ }^{+}$CD11 b $b^{+}$neutrophils. (B) Scatter plots showing ratios of CD45.2 $2^{+}$to CD45.1+ neutrophils. (C) Representative FACS plots showing CD4 and CD8 staining of live gated thymocytes (left panel) and CD45.1 and 45.2 staining of $\mathrm{CD}_{4}{ }^{+} \mathrm{CD} 8^{+}$DP thymocytes (right panel). (D) Representative FACS plot showing CD1dTet and TCR $\beta$ staining (left panel) of live gated Lin-thymocytes and CD45.1 and 45.2 staining of gated CD1dTet ${ }^{+}$TCR $\beta^{+}$iNKT cells (top right panel) and CD1dTet- ${ }^{-}$CR $\beta^{+}$non-iNKT cells (bottom right panel). (E) Representative FACS plot showing CD45.1 and 45.2 staining of live gated CD1dTet ${ }^{+}$TCR $^{+}{ }^{+}$iNKT cells from the spleen and liver. (F) CD45.2/CD45.1 ratios of indicated populations of cells. Data shown are representative or pooled from five experiments. One chimeric mouse was examined in each experiment.

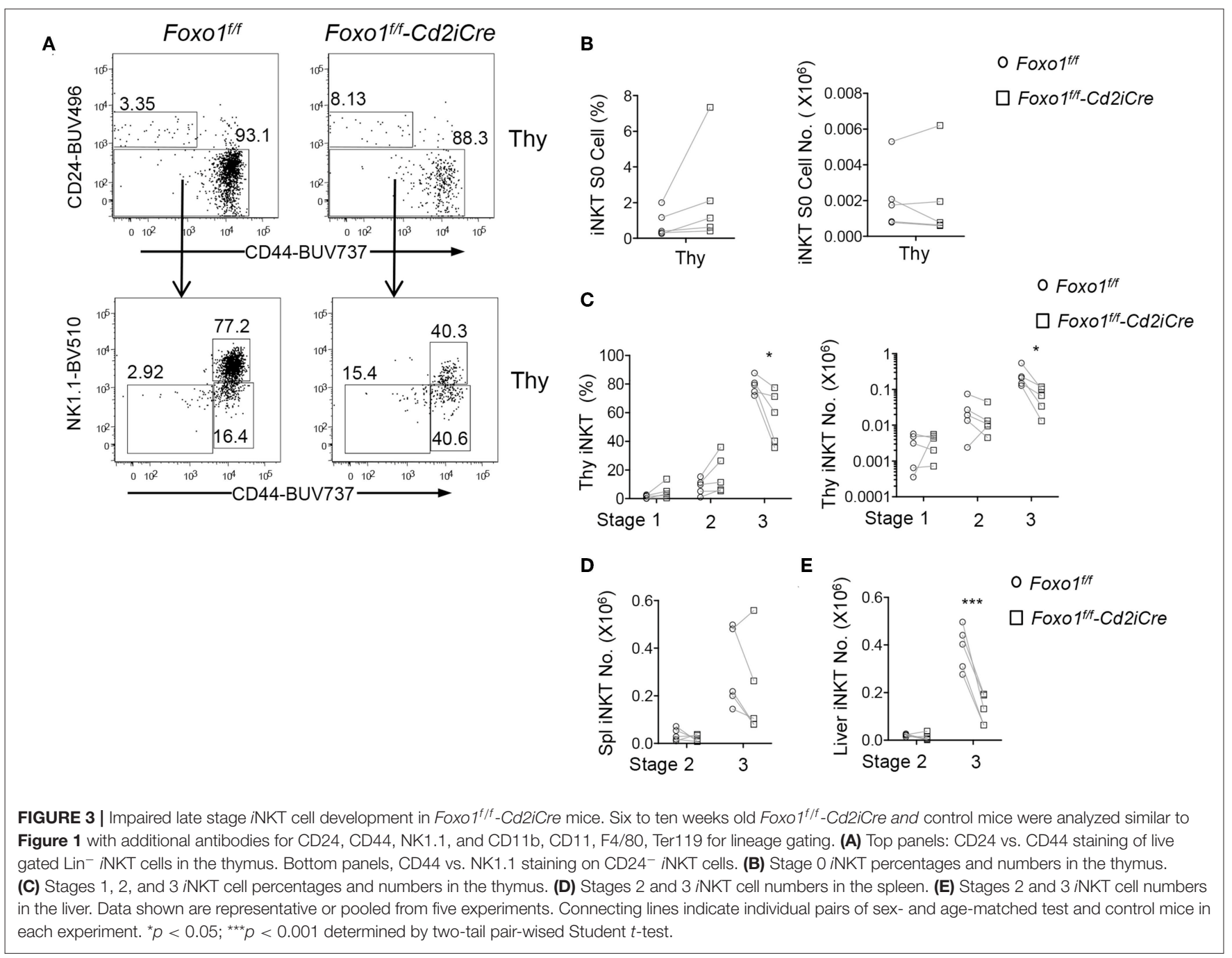

we further examined whether Foxo1 intrinsically controls $i$ NKT cell effector lineage differentiation using the mixed BM chimeric mice described in Figure 2. Similar to data shown in Figure 5, the percentages of $i$ NKT1 were decreased but $i$ NKT17 and, to certain extent, $i$ NKT2 were increased within CD45.2 ${ }^{+}$Foxo1KO $i$ NKT cells (Figures 6A,B). Additionally, the Foxo1KO to WT ratios of $i$ NKT1, $i$ NKT2, and $i$ NKT17 cells were 0.077:1, 0.36:1, and 1.1:1, respectively (Figure 6C). Because the Foxo1KO/WT $i$ NKT17 ratios (1.1:1) were greater than stage $2 i \mathrm{NKT}$ ratios $(0.35: 1$, Figure 4D), it suggested that Foxo1KO $i$ NKT17 differentiation was enhanced and that Foxol deficiency intrinsically inhibited $i$ NKT1 but promoted $i$ NKT17 differentiation.

In Foxo1KO mice, $i$ NKT1 cells but not $i$ NKT2 or $i$ NKT17 cells were prone to death compared with WT iNKT cells
(Figure 6D). ROS levels were weakly increased in stage $3 i \mathrm{NKT}$ cells (Figure 6E), which might contribute increased death and decreases of $i$ NKT1 cells as most stage $3 i$ NKT cells are $i$ NKT1 cells. Foxo1 inhibits T-bet expression in NK cells (60). Within Foxo1KO $i$ NKT1 cells, T-bet expression was increased compared with WT controls, suggesting that Foxol also inhibited Tbet expression in $i$ NKT cells (Figure 6F). Additionally, CD122, the IL2/15R $\beta$ chain that mediates IL15 signal to positively regulate T-bet expression and to promote $i$ NKT1 differentiation and survival $(61,62)$, was expressed at similar levels between WT and Foxo1KO iNKT1 cells (Figure 6F), suggesting that the reduction of Foxo1KO $i$ NKT1 cells was unlikely due to altered T-bet or CD122 expression. ROR $\gamma \mathrm{t}$ is crucial $i \mathrm{NKT} 17$ differentiation (18). ROR $\gamma$ t levels were not obviously changed 


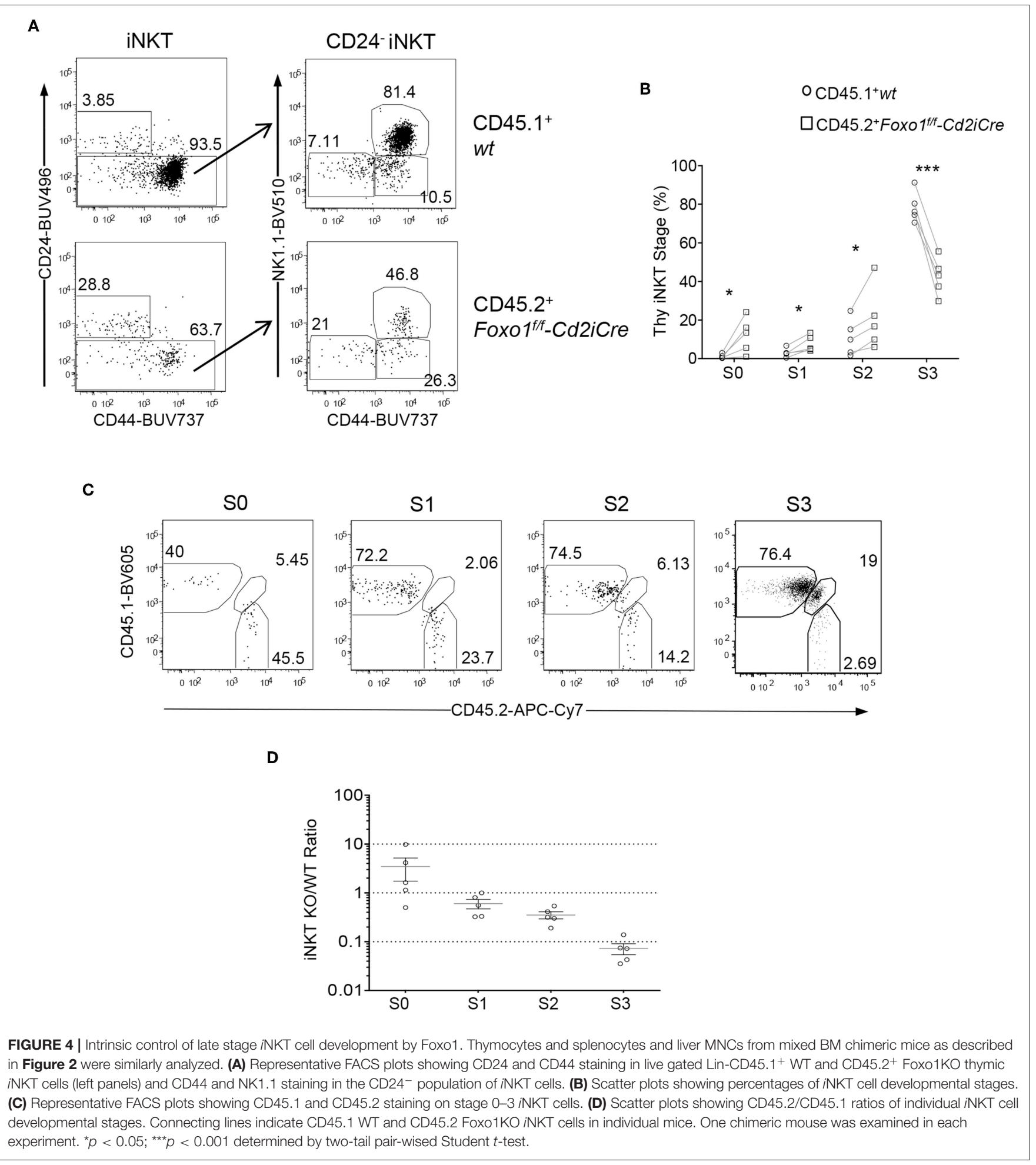

in Foxo1KO iNKT17 cells or in DP thymocytes (Figure 6F). IL7 receptor (IL7R) signal and ICOS costimulatory signal promote $i$ NKT17 lineage differentiation/homeostasis $(8,61$, 63). However, both IL7R $\alpha$ and ICOS levels were reduced in $i$ NKT cells at different stages (Figure 6G), suggesting that Foxol deficiency alleviated the requirement of these signals for $i$ NKT17 cells and might promote $i$ NKT17 lineage via other mechanisms. 

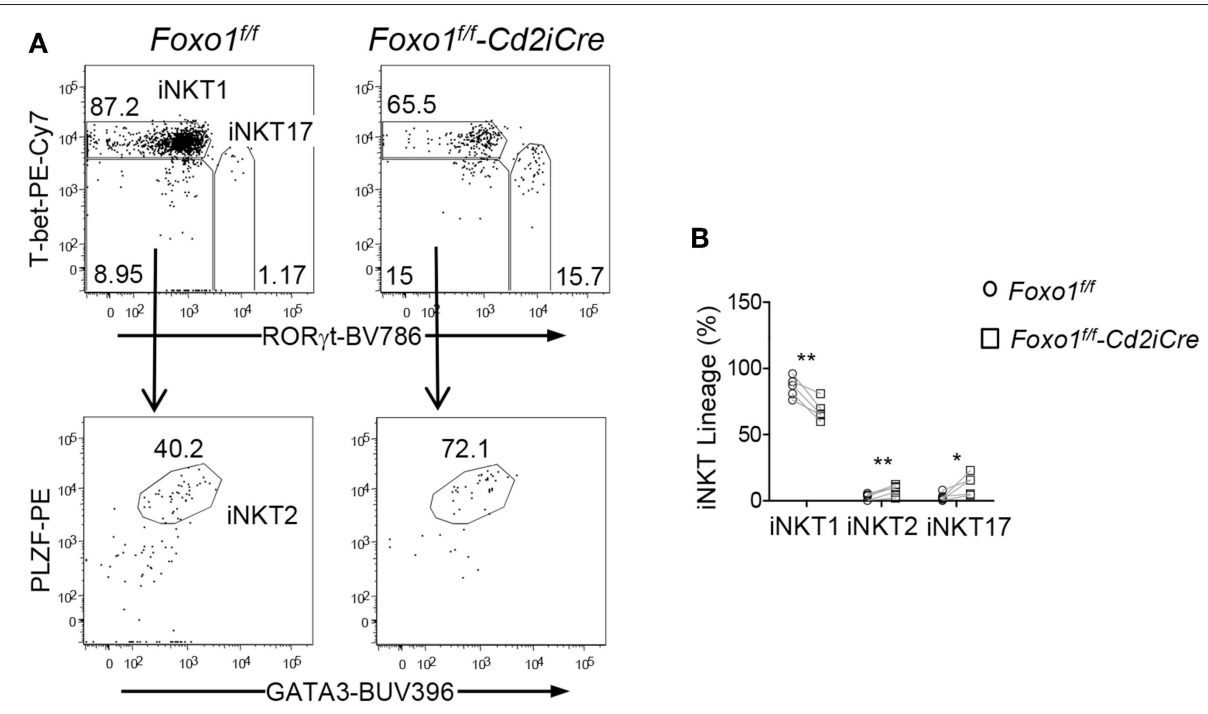

FIGURE 5 | Selective impairment of $i$ NKT1 differentiation in Foxo1 deficient mice. (A) Top panels: T-bet and ROR $\gamma$ t staining of thymic $i$ NKT cells. Bottom panels: PLZF and GATA3 staining of ROR $\gamma^{-}{ }^{-}$T-bet $^{-}$iNKT cells. (B) Percentages of $i$ NKT effector lineages. Data shown are representative or pooled from five experiments. Connecting lines indicate individual pairs of sex- and age-matched test and control mice in each experiment. One pair of mice was examined in each experiment. ${ }^{*} p<0.05 ;{ }^{* *} p<0.01$ determined by two-tail pair-wised Student $t$-test.

\section{DISCUSSION}

$i$ NKT cells differentiate to multiple effector lineages that play distinct roles in immune responses and diseases. Evidence suggests that $i \mathrm{NKT} 1$ and $i \mathrm{NKT} 17$ are competing lineages during $i \mathrm{NKT}$ effector differentiation. Both intrinsic program and environmental factors are both involved in control the balance between $i$ NKT1 and $i$ NKT17 cells $(8,15,63-67)$. In this report, we demonstrated that deficiency of Foxol intrinsically inhibited $i$ NKT1 but enhanced $i$ NKT17 differentiation without obviously affecting early $i$ NKT cell development, suggesting that Foxo1 controls $i \mathrm{NKT}$ effector lineage fate decision.

In Foxo $1^{f / f}$-Cd2iCre mice, stage 0,1 , and $2 i$ NKT cell numbers are not obviously different from WT control mice and only stage $3 i \mathrm{NKT}$ cell numbers and percentages were decreased. In mixed BM chimeric mice reconstituted with Foxo ${ }^{f / f}$-Cd2iCre and congenic WT BM cells, Foxo1KO to WT ratios of stage $0 i$ NKT cells are slightly increased compared with the ratios of $\mathrm{CD}^{+} \mathrm{CD}^{+}$thymocytes. Thus, Foxol is dispensable for early $i$ NKT cell development. However, other members of the Foxo subfamily are also expressed in developing thymocytes, our data do not rule out the possibility that those factors may function redundantly with Foxol and compensate for its deficiency during early $i$ NKT cell development. Further studies with compound deficiency of Foxol and other family members are needed to fully rule out a role of Foxol in early $i$ NKT cell development.

Foxol deficiency leads to considerable decreases of $\mathrm{CD}_{4} 4^{+} \mathrm{NK} 1.1^{+} \mathrm{T}_{\text {-bet }}{ }^{+} i \mathrm{NKT} 1$ cells but increases of $\mathrm{CD} 44^{+} \mathrm{NK} 1.1^{-} \mathrm{ROR}_{\gamma \mathrm{t}^{+}} i \mathrm{NKT} 17$ cells. $i \mathrm{NKT} 1$ cell percentages and numbers are both decreased, revealed a positive role of Foxol in promoting $i$ NKT1 differentiation/ maintenance. The increases of $i$ NKT17 cells in the absence of Foxol are not solely resulted from decreases of $i$ NKT1 cells and consequent increases of $i$ NKT17 ratios. The Foxo1KO to WT ratios of $i$ NKT17 cells are significantly overrepresented compared with those of stage 1 and $2 i$ NKT cells in mixed BM chimeric mice, indicating that Foxo1 negatively controls $i$ NKT17 differentiation. Thus, Foxo1 plays an intrinsic role in controlling $i \mathrm{NKT} 1 / 17$ effector fate decision and may rheostat the balance between these two $i \mathrm{NKT}$ effector lineages.

Numerous mechanisms have been found to control $i$ NKT1/17 lineage differentiation. Many transcription factors and regulators such as cMAF, Runx1, MED2/3, and NKAP are important for $i$ NKT17 differentiation (68-74), while the epigenetic modifiers of the TET-family dioxygenases inhibit $i$ NKT17 but promote $i$ NKT1 differentiation (67). Foxo1 deficient $i$ NKT1 but not $i \mathrm{NKT} 2 / 17$ cells were prone to death and contained increased ROS, suggesting that Foxo1 might regulate ROS production to promote $i$ NKT1 cell survival. IL15R signal is critical for $i$ NKT1 cell differentiation and homeostasis in part by increasing T-bet expression $(61,62)$. We have found IL15R $\beta$ chain expression is not reduced in Foxo1KO $i$ NKT1 cells. Thus, Foxo1 deficiency may cause $i$ NKT1 defect via mechanisms other than altered expression of T-bet or CD122. IL7R signal and ICOS costimulatory signal promote $i$ NKT17 cell homeostasis $(8,61,63)$. Both IL7R $\alpha$ and ICOS levels were decreased in Foxo1KO $i$ NKT cells. In conventional $\mathrm{T}$ cells, Foxo1 binds to Il7ra and Icos loci to promote their transcription $(48,75)$. Foxo1 may function similarly to promote expression of these molecules in iNKT cells. However, it is unlikely that the decreased expression of IL7R and ICOS causes enhanced $i$ NKT17 differentiation in Foxo1KO mice. Although ICOS and IL7R are not crucial for $i \mathrm{NKT} 1$ differentiation, our data do not rule out 

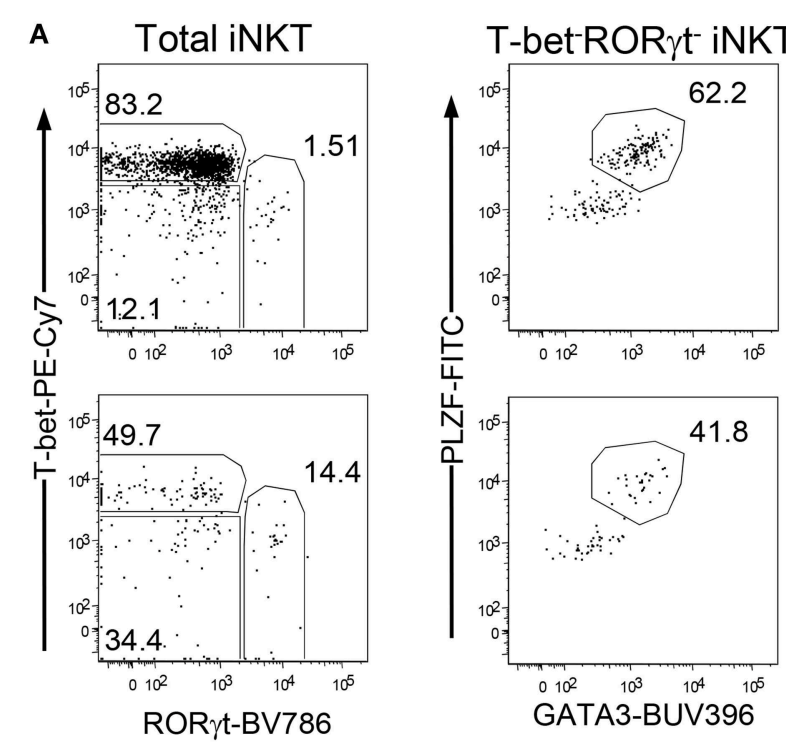

B

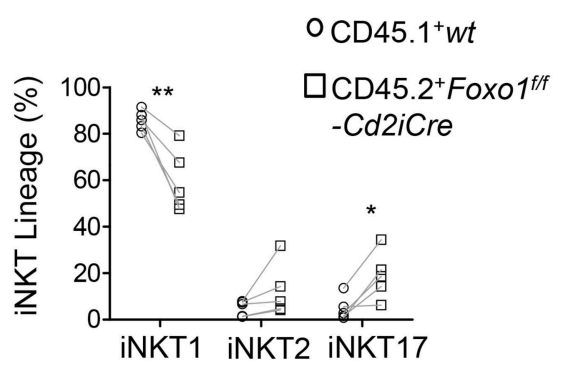

CD45.2+ Foxo1 ${ }^{\text {ff- }}-$ Cd2iCre

C

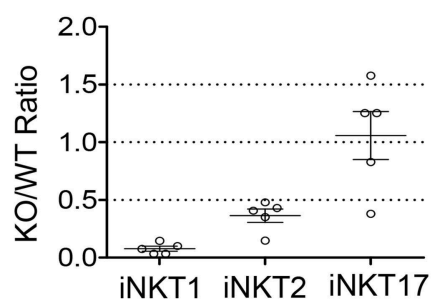

D

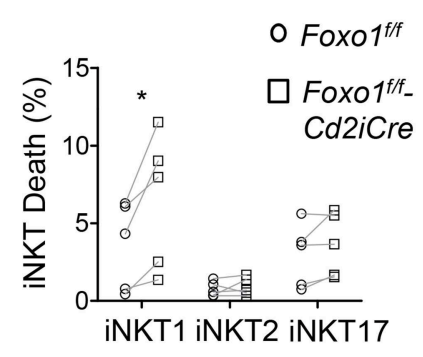

E

$\mathbf{F}$
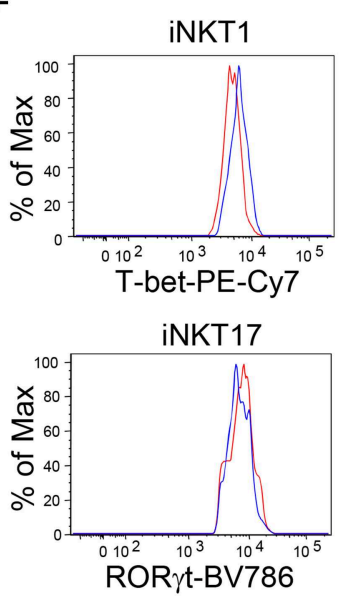

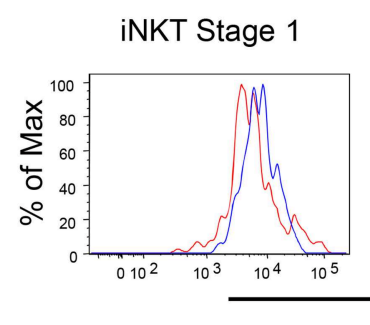

iNKT Stage 2

iNKT Stage 3

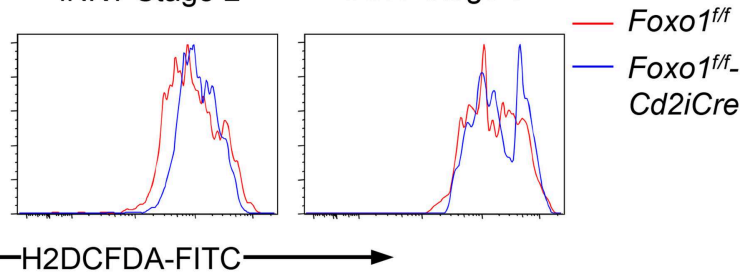

G

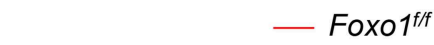

- Foxo1 $1^{\text {fff-Cd2iCre }}$

iNKT1

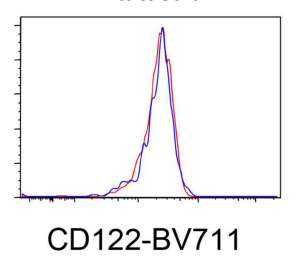

iNKT Stage 1

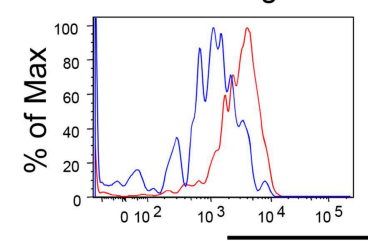

iNKT Stage 2

iNKT Stage 3
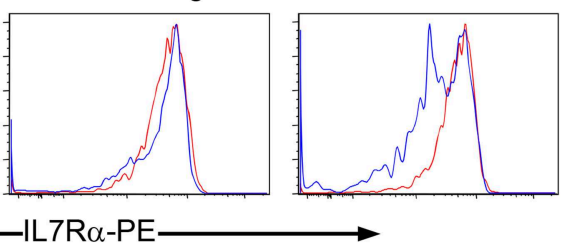

DP Thymocyte
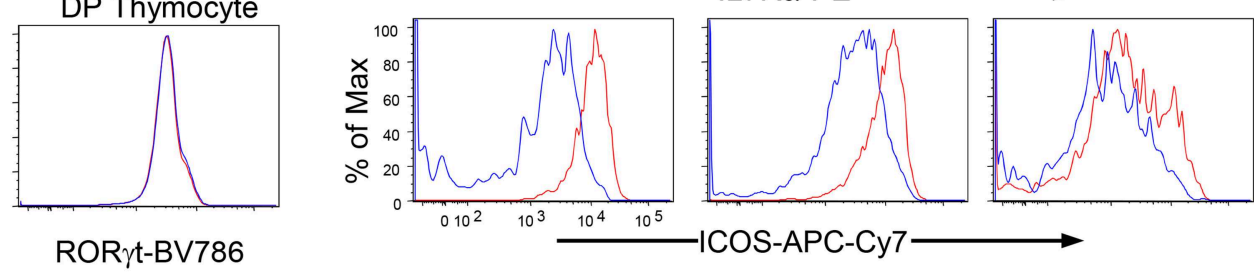

FIGURE 6 | Intrinsic control of iNKT cell effector lineage differentiation by Foxo1. (A-C) Thymocytes from mixed BM chimeric mice as described in Figure 2 were similarly analyzed. (A) Representative FACS plots showing RORyt and T-bet staining in gated CD45.1+ WT and CD45.2+ Foxo1KO iNKT cells (left panels) and PLZF and GATA3 staining in gated ROR $\gamma \mathrm{t}^{-}$T-bet $^{-}{ }^{-}$NKT cells. (B) Scatter plots showing percentages of iNKT effector lineages. (C) Scatter plots showing CD45.2

Foxo1KO/CD45.1WT ratios of individual iNKT effector lineages. Data shown are representative or pooled from five experiments. Connecting lines indicate CD45.1 WT and CD45.2 Foxo1KO INKT cells in individual mice. One chimeric mouse was examined in each experiment. ${ }^{*} p<0.05 ;{ }^{* *} p<0.01$ determined by two-tail pair-wised Student $t$-test. (D-G) Two to three weeks old Foxo $1^{f / f}$-Cd2iCre and Foxo $1^{f / f}$ mice were analyzed for thymic $i$ NKT cells by flow cytometry. (D) Death rates of $i N K T$ effector lineages detected by Live/Dead ${ }^{\mathrm{T} M}$ Fixable Violet Dead Cell Stain. $N=5 .{ }^{*} p<0.05$ determined by two-tail pair-wised Student $t$-test. (E) Overlaid histograms show ROS levels in stages 1-3 iNKT cells. (F) Overlaid histograms show T-bet and CD122 levels in iNKT1 cells and RORyt levels in iNKT17 cells and in DP thymocytes. (G) Overlaid histograms show IL7R $\alpha$ and ICOS levels in stages 1-3 INKT cells. Data in (E-G) are representative of three experiments. 
the possibility that decreased expression of these molecules may impair $i$ NKT1 lineage differentiation/homeostasis in the context of Foxol deficiency.

Foxol inhibits Th17 differentiation and IL-17A expression by directly suppressing transcription of ROR $\gamma \mathrm{t}$ and IL-23R expression and by interacting with $\operatorname{ROR} \gamma t(44,47,76)$. Although such mechanisms could operate similarly $i$ NKT cells, we do not observe increased ROR $\gamma$ t protein levels in Foxo1KO $i$ NKT17 cells. It is interesting to note that Foxol inhibits T-bet mediated effector differentiation of CD8 T cells and Th1 differentiation $(55,77)$ and binds to the $T b \times 21$ promoter to inhibit T-bet expression in NK cells (60). In Foxol deficient $i$ NKT1 cells, Tbet levels were increased, suggesting that Foxo1 may also directly suppress T-bet expression in $i$ NKT cells. However, increased Tbet expression should not be the reason for deficiency of $i$ NKT1 cells in Foxo1KO mice.

Foxo1 is regulated by multiple mechanisms. Akt, SGK1, and the serine/threonine kinase CK2 phosphorylate Foxo1 to inhibit its nuclear localization and activity. mTOR regulates $i$ NKT1 and $i$ NKT17 differentiation via mTOR complex 1 (mTORC1) and mTORC2 and their tight regulation by the tumor suppressor TSC1 ensures proper $i \mathrm{NKT} 1 / 17$ balance $(8$, $66,78,79)$. mTORC2 phosphorylates Akt and SGK1 to enhance their enzyme activities (80-82). Deficiency of either Akt2 or mTORC2 causes decreases of $i$ NKT17 cells, which correlates with decreased Foxol phosphorylation or increased Foxol nuclear localization $(66,83)$. The data we report here provide direct evidence that Foxo 1 plays critical roles in $i$ NKT cell development and effector lineage differentiation. Although the importance of SGK1 and CK2 in iNKT cells has been unclear, both SGK1 and CK2 promote Th17 differentiation at least partially through inhibition of Foxo1 $(45,84,85)$. Our data together with these

\section{REFERENCES}

1. Chandra S, Kronenberg M. Activation and function of iNKT and MAIT cells. Adv Immunol. (2015) 127:145-201. doi: 10.1016/bs.ai.2015.03.003

2. Yang W, Gorentla B, Zhong XP, Shin J. mTOR and its tight regulation for iNKT cell development and effector function. Mol Immunol. (2015) 68:536-45. doi: 10.1016/j.molimm.2015.07.022

3. Brennan PJ, Brigl M, Brenner MB. Invariant natural killer T cells: an innate activation scheme linked to diverse effector functions. Nat Rev Immunol. (2013) 13:101-17. doi: 10.1038/nri3369

4. Wu L, Van Kaer L. Natural killer T cells in health and disease. Front Biosci. (2011) 3:236-51. doi: 10.2741/s148

5. Zhang J, Bedel R, Krovi SH, Tuttle KD, Zhang B, Gross J, et al. Mutation of the Traj18 gene segment using TALENs to generate Natural Killer T cell deficient mice. Sci Rep. (2016) 6:27375. doi: 10.1038/srep27375

6. Dashtsoodol N, Shigeura T, Ozawa R, Harada M, Kojo S, Watanabe T, et al. Generation of novel Traj18-deficient mice lacking Valpha14 natural killer $\mathrm{T}$ cells with an undisturbed $\mathrm{T}$ cell receptor alpha-chain repertoire. PLoS ONE. (2016) 11:e0153347. doi: 10.1371/journal.pone.0153347

7. Chandra S, Zhao M, Budelsky A, de Mingo Pulido A, Day J, Fu Z, et al. A new mouse strain for the analysis of invariant NKT cell function. Nat Immunol. (2015) 16:799-800. doi: 10.1038/ni.3203

8. Wu J, Yang J, Yang K, Wang H, Gorentla B, Shin J, et al. iNKT cells require TSC1 for terminal maturation and effector lineage fate decisions. J Clin Invest. (2014) 124:1685-98. doi: 10.1172/JCI69780 observations indicate that Foxol may integrate signals from mTORC2/Akt/SGK1 and other enzymes to control $i$ NKT cell effector lineage fate decision.

\section{DATA AVAILABILITY STATEMENT}

The datasets generated for this study are available on request to the corresponding author.

\section{ETHICS STATEMENT}

The protocol was approved by the Duke University Institute Animal Care and Use Committee.

\section{AUTHOR CONTRIBUTIONS}

HT and LL designed and performed experiments, analyzed data, and were involved in manuscript preparation. YG and ZW were involved in data analyses and manuscript preparation. X-PZ conceived the project, designed experiments, analyzed data, and wrote the manuscript.

\section{FUNDING}

This study was supported by the National Institutes of Health (AI079088 and AI101206) to X-PZ.

\section{ACKNOWLEDGMENTS}

We thank the NIH Tetramer Core Facility for CD1d tetramers and the flow cytometry core facility at Duke University for services.
9. Shin J, Wang S, Deng W, Wu J, Gao J, Zhong XP. Mechanistic target of rapamycin complex 1 is critical for invariant natural killer T-cell development and effector function. Proc Natl Acad Sci USA. (2014) 111:E77683. doi: $10.1073 /$ pnas.1315435111

10. Shen S, Wu J, Srivatsan S, Gorentla BK, Shin J, Xu L, et al. Tight regulation of diacylglycerol-mediated signaling is critical for proper invariant NKT cell development. J Immunol. (2011) 187:2122-9. doi: 10.4049/jimmunol.1100495

11. Shen S, Chen Y, Gorentla BK, Lu J, Stone JC, Zhong XP. Critical roles of RasGRP1 for invariant NKT cell development. J Immunol. (2011) 187:446773. doi: 10.4049/jimmunol.1003798

12. Hu T, Gimferrer I, Simmons A, Wiest D, Alberola-Ila J. The Ras/MAPK pathway is required for generation of iNKT cells. PLoS ONE. (2011) 6:e19890. doi: 10.1371/journal.pone.0019890

13. Bendelac A, Savage PB, Teyton L. The biology of NKT cells. Annu Rev Immunol. (2007) 25:297-336. doi: 10.1146/annurev.immunol.25.022106.141711

14. Godfrey DI, Stankovic S, Baxter AG. Raising the NKT cell family. Nat Immunol. (2010) 11:197-206. doi: 10.1038/ni.1841

15. Lee YJ, Holzapfel KL, Zhu J, Jameson SC, Hogquist KA. Steady-state production of IL-4 modulates immunity in mouse strains and is determined by lineage diversity of iNKT cells. Nat Immunol. (2013) 14:1146-54. doi: $10.1038 /$ ni.2731

16. Chang PP, Barral P, Fitch J, Pratama A, Ma CS, Kallies A, et al. Identification of Bcl-6-dependent follicular helper NKT cells that provide cognate help for B cell responses. Nat Immunol. (2011) 13:35-43. doi: 10.1038/ni.2166 
17. Rampuria P, Lang ML. CD1d-dependent expansion of NKT follicular helper cells in vivo and in vitro is a product of cellular proliferation and differentiation. Int Immunol. (2015) 27:253-63. doi: 10.1093/intimm/dxv007

18. Michel ML, Mendes-da-Cruz D, Keller AC, Lochner M, Schneider E, Dy M, et al. Critical role of ROR-gammat in a new thymic pathway leading to IL-17producing invariant NKT cell differentiation. Proc Natl Acad Sci USA. (2008) 105:19845-50. doi: 10.1073/pnas.0806472105

19. Matsuda Y, Toda M, Kato T, Kuribayashi K, Kakimi K. Fulminant liver failure triggered by therapeutic antibody treatment in a mouse model. Int J Oncol. (2006) 29:1119-25. doi: 10.3892/ijo.29.5.1119

20. Michel ML, Keller AC, Paget C, Fujio M, Trottein F, Savage PB, et al. Identification of an IL-17-producing NK1.1 (neg) iNKT cell population involved in airway neutrophilia. J Exp Med. (2007) 204:995-1001. doi: 10.1084 /jem.20061551

21. Tonti E, Fedeli M, Napolitano A, Iannacone M, von Andrian UH, Guidotti LG, et al. Follicular helper NKT cells induce limited B cell responses and germinal center formation in the absence of $\mathrm{CD}^{+} \mathrm{T}$ cell help. J Immunol. (2012) 188:3217-22. doi: 10.4049/jimmunol.1103501

22. Lynch L, Michelet X, Zhang S, Brennan PJ, Moseman A, Lester C, et al. Regulatory iNKT cells lack expression of the transcription factor PLZF and control the homeostasis of $\mathrm{T}$ (reg) cells and macrophages in adipose tissue. Nat Immunol. (2015) 16:85-95. doi: 10.1038/ni.3047

23. Sag D, Krause P, Hedrick CC, Kronenberg M, Wingender G. IL-10-producing NKT10 cells are a distinct regulatory invariant NKT cell subset. J Clin Invest. (2014) 124:3725-40. doi: 10.1172/JCI72308

24. Matsuda JL, Zhang Q, Ndonye R, Richardson SK, Howell AR, Gapin, L. T-bet concomitantly controls migration, survival, and effector functions during the development of Valpha14i NKT cells. Blood. (2006) 107:2797-805. doi: 10.1182/blood-2005-08-3103

25. Kim HY, Pichavant M, Matangkasombut P, Koh YI, Savage PB, DeKruyff $\mathrm{RH}$, et al. The development of airway hyperreactivity in T-bet-deficient mice requires CD1d-restricted NKT cells. J Immunol. (2009) 182:3252-3261. doi: 10.4049/jimmunol.0803339

26. Coquet JM, Chakravarti S, Kyparissoudis K, McNab FW, Pitt LA, McKenzie BS, et al. Diverse cytokine production by NKT cell subsets and identification of an IL-17-producing CD $4^{-} \mathrm{NK} 1.1^{-}$NKT cell population. Proc Natl Acad Sci USA. (2008) 105:11287-92. doi: 10.1073/pnas.0801631105

27. Milpied P, Massot B, Renand A, Diem S, Herbelin A, Leite-de-Moraes M, et al. IL-17-producing invariant NKT cells in lymphoid organs are recent thymic emigrants identified by neuropilin-1 expression. Blood. (2011) 118:2993-3002. doi: 10.1182/blood-2011-01-329268

28. Watarai H, Sekine-Kondo E, Shigeura T, Motomura Y, Yasuda T, Satoh $\mathrm{R}$, et al. Development and function of invariant natural killer $\mathrm{T}$ cells producing T (h) 2- and T (h) 17-cytokines. PLoS Biol. (2012) 10:e1001255. doi: 10.1371/journal.pbio.1001255

29. Gaya M, Barral P, Burbage M, Aggarwal S, Montaner B, Warren Navia A, et al. Initiation of antiviral B cell immunity relies on innate signals from spatially positioned NKT cells. Cell. (2018) 172:517-33 e520. doi: 10.1016/j.cell.2017.11.036

30. Liew PX, Lee WY, Kubes P. iNKT cells orchestrate a switch from inflammation to resolution of sterile liver injury. Immunity. (2017) 47:752-65 e755. doi: 10.1016/j.immuni.2017.09.016

31. Lynch L, Nowak M, Varghese B, Clark J, Hogan AE, Toxavidis V, et al. Adipose tissue invariant NKT cells protect against diet-induced obesity and metabolic disorder through regulatory cytokine production. Immunity. (2012) 37:574-87. doi: 10.1016/j.immuni.2012.06.016

32. Cabrera-Ortega AA, Feinberg D, Liang Y, Rossa C Jr, Graves DT. The role of Forkhead Box 1 (FOXO1) in the immune system: dendritic cells, T cells, B cells, and hematopoietic stem cells. Crit Rev Immunol. (2017) 37:1-13. doi: 10.1615/CritRevImmunol.2017019636

33. Silhan J, Vacha P, Strnadova P, Vecer J, Herman P, Sulc M. 14-3-3 protein masks the DNA binding interface of forkhead transcription factor FOXO4. J Biol Chem. (2009) 284:19349-60. doi: 10.1074/jbc.M109.002725

34. Ouyang W, Li MO. Foxo: in command of T lymphocyte homeostasis and tolerance. Trends Immunol. (2011) 32:26-33. doi: 10.1016/j.it.2010.10.005

35. Xiao W, Dong G, Pacios S, Alnammary M, Barger LA, Wang Y, et al. FOXO1 deletion reduces dendritic cell function and enhances susceptibility to periodontitis. Am J Pathol. (2015) 185:1085-1093. doi: 10.1016/j.ajpath.2014.12.006

36. Dong G, Wang Y, Xiao W, Pacios Pujado S, Xu F, Tian C, et al. FOXO1 regulates dendritic cell activity through ICAM-1 and CCR7. J Immunol. (2015) 194:3745-3755. doi: 10.4049/jimmunol.1401754

37. Amin RH, Schlissel MS. Foxo1 directly regulates the transcription of recombination-activating genes during B cell development. Nat Immunol. (2008) 9:613-22. doi: 10.1038/ni.1612

38. Herzog S, Hug E, Meixlsperger S, Paik JH, DePinho RA, Reth M, et al. SLP-65 regulates immunoglobulin light chain gene recombination through the PI(3)K-PKB-Foxo pathway. Nat Immunol. (2008) 9:623-31. doi: $10.1038 /$ ni. 1616

39. Lin YC, Jhunjhunwala S, Benner C, Heinz S, Welinder E, Mansson R, et al. A global network of transcription factors, involving E2A, EBF1 and Foxo1, that orchestrates B cell fate. Nat Immunol. (2010) 11:635-43. doi: 10.1038/ni.1891

40. Kerdiles YM, Beisner DR, Tinoco R, Dejean AS, Castrillon DH, DePinho $\mathrm{RA}$, et al. Foxo1 links homing and survival of naive $\mathrm{T}$ cells by regulating $\mathrm{L}$ selectin, CCR7 and interleukin 7 receptor. Nat Immunol. (2009) 10:176-84 doi: 10.1038/ni.1689

41. Luo CT, Liao W, Dadi S, Toure A, Li, MO. Graded Foxol activity in Treg cells differentiates tumour immunity from spontaneous autoimmunity. Nature. (2016) 529:532-6. doi: 10.1038/nature16486

42. Kerdiles YM, Stone EL, Beisner DL, McGargill MA, Ch'en IL, Stockmann C, et al. Foxo transcription factors control regulatory $\mathrm{T}$ cell development and function. Immunity. (2010) 33:890-904. doi: 10.1016/j.immuni.2010.12.002

43. Ouyang W, Beckett O, Ma Q, Paik JH, DePinho RA, Li MO. Foxo proteins cooperatively control the differentiation of Foxp $3^{+}$regulatory $\mathrm{T}$ cells. Nat Immunol. (2010) 11:618-27. doi: 10.1038/ni.1884

44. Ichiyama K, Gonzalez-Martin A, Kim BS, Jin HY, Jin W, Xu W, et al. The microRNA-183-96-182 cluster promotes $\mathrm{T}$ helper 17 cell pathogenicity by negatively regulating transcription factor Foxol expression. Immunity. (2016) 44:1284-98. doi: 10.1016/j.immuni.2016.05.015

45. Gibson SA, Yang W, Yan Z, Qin H, Benveniste EN. CK2 controls Th17 and regulatory $\mathrm{T}$ cell differentiation through inhibition of FoxO1. J Immunol. (2018) 201:383-92. doi: 10.4049/jimmunol.1701592

46. Liu L, Liu Y, Yuan M, Xu L, Sun, H. Elevated expression of microRNA-873 facilitates Th17 differentiation by targeting forkhead box O1 (Foxo1) in the pathogenesis of systemic lupus erythematosus. Biochem Biophys Res Commun. (2017) 492:453-60. doi: 10.1016/j.bbrc.2017.08.075

47. Laine A, Martin B, Luka M, Mir L, Auffray C, Lucas B, et al. Foxol is a T cell-intrinsic inhibitor of the RORgammat-Th17 program. J Immunol. (2015) 195:1791-803. doi: 10.4049/jimmunol.1500849

48. Stone EL, Pepper M, Katayama CD, Kerdiles YM, Lai CY, Emslie $\mathrm{E}$, et al. ICOS coreceptor signaling inactivates the transcription factor FOXO1 to promote Tfh cell differentiation. Immunity. (2015) 42:239-51. doi: 10.1016/j.immuni.2015.01.017

49. Weber JP, Fuhrmann F, Feist RK, Lahmann A, Al Baz MS, Gentz LJ, et al. ICOS maintains the $T$ follicular helper cell phenotype by down-regulating Kruppellike factor 2. J Exp Med. (2015) 212:217-33. doi: 10.1084/jem.20141432

50. Zeng H, Cohen S, Guy C, Shrestha S, Neale G, Brown SA, et al. mTORC1 and mTORC2 kinase signaling and glucose metabolism drive follicular helper $\mathrm{T}$ cell differentiation. Immunity. (2016) 45:540-54. doi: 10.1016/j.immuni.2016.08.017

51. Buttrick TS, Wang W, Yung C, Trieu KG, Patel K, Khoury SJ, et al. Foxo1 promotes Th9 cell differentiation and airway allergy. Sci Rep. (2018) 8:818. doi: 10.1038/s41598-018-19315-Z

52. Malik S, Sadhu S, Elesela S, Pandey RP, Chawla AS, Sharma D, et al. Transcription factor Foxo1 is essential for IL-9 induction in T helper cells. Nat Commun. (2017) 8:815. doi: 10.1038/s41467-017-00674-6

53. Bi E, Ma X, Lu Y, Yang M, Wang Q, Xue G, et al. Foxol and Foxp1 play opposing roles in regulating the differentiation and antitumor activity of Th9 cells programmed by IL-7. Sci Signal. (2017) 10:eaak9741. doi: 10.1126/scisignal.aak9741

54. Zhang L, Tschumi BO, Lopez-Mejia IC, Oberle SG, Meyer M, Samson G. Mammalian target of rapamycin complex 2 controls CD8 T cell memory differentiation in a Foxol-dependent manner. Cell Rep. (2016) 14:1206-17. doi: 10.1016/j.celrep.2015.12.095 
55. Rao RR, Li Q, Gubbels Bupp MR, Shrikant PA. Transcription factor Foxo1 represses T-bet-mediated effector functions and promotes memory CD8(+) $\mathrm{T}$ cell differentiation. Immunity. (2012) 36:374-87. doi: 10.1016/j.immuni.2012.01.015

56. Kim MV, Ouyang W, Liao W, Zhang MQ, Li MO. The transcription factor Foxo1 controls central-memory $\mathrm{CD}^{+}$Tcell responses to infection. Immunity. (2013) 39:286-97. doi: 10.1016/j.immuni.2013.07.013

57. Paik JH, Kollipara R, Chu G, Ji H, Xiao Y, Ding Z, et al. FoxOs are lineage-restricted redundant tumor suppressors and regulate endothelial cell homeostasis. Cell. (2007) 128:309-23. doi: 10.1016/j.cell.2006.12.029

58. de Boer J, Williams A, Skavdis G, Harker N, Coles M, Tolaini M, et al. Transgenic mice with hematopoietic and lymphoid specific expression of Cre. Eur J Immunol. (2003) 33:314-25. doi: 10.1002/immu.200310005

59. Luo CT, Li MO. Transcriptional control of regulatory $\mathrm{T}$ cell development and function. (2013) Trends Immunol. 34:531-9. doi: 10.1016/j.it.2013.08.003

60. Du X, de Almeida P, Manieri N, de Almeida Nagata D, Wu TD, Harden Bowles K, et al. CD226 regulates natural killer cell antitumor responses via phosphorylation-mediated inactivation of transcription factor FOXO1. Proc Natl Acad Sci USA. (2018) 115:E11731-40. doi: 10.1073/pnas.1814052115

61. Matsuda JL, Gapin L, Sidobre S, Kieper WC, Tan JT, Ceredig R, et al. Homeostasis of V alpha 14i NKT cells. Nat Immunol. (2002) 3:966-74. doi: $10.1038 /$ ni837

62. Gordy LE, Bezbradica JS, Flyak AI, Spencer CT, Dunkle A, Sun J, et al. IL15 regulates homeostasis and terminal maturation of NKT cells. J Immunol. (2011) 187:6335-45. doi: 10.4049/jimmunol.1003965

63. Webster KE, Kim HO, Kyparissoudis K, Corpuz TM, Pinget GV, Uldrich AP, et al. IL-17-producing NKT cells depend exclusively on IL-7 for homeostasis and survival. Mucosal Immunol. (2014) 7:1058-67. doi: 10.1038/mi.2013.122

64. Castillo EF, Acero LF, Stonier SW, Zhou D, Schluns KS. Thymic and peripheral microenvironments differentially mediate development and maturation of iNKT cells by IL-15 transpresentation. Blood. (2010) 116:2494-503. doi: 10.1182/blood-2010-03-277103

65. Monteiro M, Almeida CF, Agua-Doce A, Graca L. Induced IL-17-producing invariant NKT cells require activation in presence of TGF-beta and IL-1beta. J Immunol. (2013) 190:805-11. doi: 10.4049/jimmunol.1201010

66. Wei J, Yang K, Chi H. Cutting edge: Discrete functions of mTOR signaling in invariant NKT cell development and NKT17 fate decision. J Immunol. (2014) 193:4297-301. doi: 10.4049/jimmunol.1402042

67. Tsagaratou A, Gonzalez-Avalos E, Rautio S, Scott-Browne JP, Togher S, Pastor WA, et al. TET proteins regulate the lineage specification and TCR-mediated expansion of iNKT cells. Nat Immunol. (2017) 18:45-53. doi: 10.1038/ni.3630

68. Thapa P, Manso B, Chung JY, Romera Arocha S, Xue HH, Angelo DBS, et al. The differentiation of ROR-gammat expressing iNKT17 cells is orchestrated by Runx1. Sci Rep. (2017) 7:7018. doi: 10.1038/s41598-017-07365-8

69. Yu JS, Hamada M, Ohtsuka S, Yoh K, Takahashi S, Miaw SC. Differentiation of IL-17-producing invariant natural killer $\mathrm{T}$ cells requires expression of the transcription factor c-Maf. Front Immunol. (2017) 8:1399. doi: 10.3389/fimmu.2017.01399

70. Thapa P, Chen MW, McWilliams DC, Belmonte P, Constans M, Sant'Angelo DB, et al. NKAP regulates invariant NKT cell proliferation and differentiation into ROR-gammat-expressing NKT17 cells. J Immunol. (2016) 196:4987-98. doi: 10.4049/jimmunol.1501653

71. Yue X, Izcue A, Borggrefe T. Essential role of Mediator subunit Med1 in invariant natural killer T-cell development. Proc Natl Acad Sci USA. (2011) 108:17105-10. doi: 10.1073/pnas.1109095108

72. Yu S, Cantorna MT. The vitamin D receptor is required for iNKT cell development. Proc Natl Acad Sci USA. (2008) 105:5207-12. doi: 10.1073/pnas.0711558105
73. Thapa P, Romero Arocha S, Chung JY, Sant'Angelo DB, Shapiro VS. Histone deacetylase 3 is required for iNKT cell development. Sci Rep. (2017) 7:5784. doi: 10.1038/s41598-017-06102-5

74. Xu Y, Sun Y, Shen H, Dai Y, Liu H, Li R, et al. Regulation of the terminal maturation of iNKT cells by mediator complex subunit 23. Nat Commun. (2018) 9:3875. doi: 10.1038/s41467-018-06372-1

75. Ouyang W, Beckett O, Flavell RA, Li MO. An essential role of the Forkhead-box transcription factor Foxol in control of $\mathrm{T}$ cell homeostasis and tolerance. Immunity. (2009) 30:358-71. doi: 10.1016/j.immuni.2009. 02.003

76. Yang X, He Q, Guo Z, Xiong F, Li Y, Pan Y, et al. MicroRNA-425 facilitates pathogenic Th17 cell differentiation by targeting forkhead box O1 (Foxo1) and is associated with inflammatory bowel disease. Biochem Biophys Res Commun. (2018) 496:352-8. doi: 10.1016/j.bbrc.2018.01.055

77. Harada Y, Harada Y, Elly C, Ying G, Paik JH, DePinho RA, et al. Transcription factors Foxo3a and Foxol couple the E3 ligase Cbl-b to the induction of Foxp3 expression in induced regulatory T cells. J Exp Med. (2010) 207:1381-91. doi: 10.1084 /jem.20100004

78. Lee YJ, Starrett GJ, Lee ST, Yang R, Henzler CM, Jameson SC, et al. Lineage-specific effector signatures of invariant NKT cells are shared amongst gammadelta T, innate lymphoid, and Th cells. J Immunol. (2016) 197:1460-70. doi: 10.4049/jimmunol.1600643

79. Wu J, Shin J, Xie D, Wang H, Gao J, Zhong XP. Tuberous sclerosis 1 promotes invariant NKT cell anergy and inhibits invariant NKT cell-mediated antitumor immunity. J Immunol. (2014) 192:2643-50. doi: $10.4049 /$ jimmunol.1302076

80. Garcia-Martinez JM, Alessi DR. mTOR complex 2 (mTORC2) controls hydrophobic motif phosphorylation and activation of serum- and glucocorticoid-induced protein kinase 1 (SGK1). Biochem J. (2008) 416:375-85. doi: 10.1042/BJ20081668

81. Dibble CC, Asara JM, Manning BD. Characterization of Rictor phosphorylation sites reveals direct regulation of mTOR complex 2 by S6K1. Mol Cell Biol. (2009). 29:5657-70. doi: 10.1128/MCB.00 735-09

82. Heikamp EB, Patel CH, Collins S, Waickman A, Oh MH, Sun IH, et al. The AGC kinase SGK1 regulates TH1 and TH2 differentiation downstream of the mTORC2 complex. Nat Immunol. (2014). 15:457-64. doi: 10.1038/ni.2867

83. Niu L, Xuan X, Wang J, Li L, Yang D, Jing Y, et al. Akt2 regulates the differentiation and function of NKT17 cells via FoxO-1-ICOS axis. Front Immunol. (2018). 9:1940. doi: 10.3389/fimmu.2018.01940

84. Kleinewietfeld M, Manzel A, Titze J, Kvakan H, Yosef N, Linker RA, et al. Sodium chloride drives autoimmune disease by the induction of pathogenic Th17 cells. Nature. (2013). 496:518-22. doi: 10.1038/nature11868

85. Wu C, Yosef N, Thalhamer T, Zhu C, Xiao S, Kishi Y, et al. Induction of pathogenic Th17 cells by inducible salt-sensing kinase SGK1. Nature. (2013). 496:513-7. doi: 10.1038/nature11984

Conflict of Interest: The authors declare that the research was conducted in the absence of any commercial or financial relationships that could be construed as a potential conflict of interest.

Copyright (c) 2019 Tao, Li, Gao, Wang and Zhong. This is an open-access article distributed under the terms of the Creative Commons Attribution License (CC BY). The use, distribution or reproduction in other forums is permitted, provided the original author(s) and the copyright owner(s) are credited and that the original publication in this journal is cited, in accordance with accepted academic practice. No use, distribution or reproduction is permitted which does not comply with these terms. 